\title{
pH-mediated control over the mesostructure of ordered mesoporous materials templated by polyion complex micelles
}

\author{
Emilie Molina ${ }^{1}$, Mélody Mathonnat ${ }^{1,2}$, Jason Richard ${ }^{1}$, Patrick Lacroix-Desmazes ${ }^{1}$, \\ Martin In², Philippe Dieudonné2 ${ }^{2}$ Thomas Cacciaguerra ${ }^{1}$, Corine Gérardin ${ }^{*}$ \\ and Nathalie Marcotte*1
}

Open Access

\author{
Full Research Paper \\ Address: \\ ${ }^{1}$ ICGM UMR 5253 CNRS - Université de Montpellier - ENSCM, \\ ENSCM 240 Av Pr E. Jeanbrau, 34296 Montpellier cedex 5, France, \\ and ${ }^{2}$ Laboratoire Charles Coulomb, UMR 5221 CNRS - Université de \\ Montpellier, 34095 Montpellier, France \\ Email: \\ Corine Gérardin* - corine.gerardin@enscm.fr; Nathalie Marcotte* - \\ nathalie.marcotte@enscm.fr \\ * Corresponding author \\ Keywords: \\ double-hydrophilic block copolymer; hybrid organic-inorganic \\ interface; mesoporous materials; nanostructured materials; polyion \\ complex micelles; polyion electrostatic complexation
}

Beilstein J. Nanotechnol. 2019, 10, 144-156. doi:10.3762/bjnano.10.14

Received: 11 September 2018

Accepted: 27 December 2018

Published: 11 January 2019

This article is part of the thematic issue "Advanced hybrid nanomaterials". Guest Editor: A. Taubert

(C) 2019 Molina et al.; licensee Beilstein-Institut. License and terms: see end of document.

\begin{abstract}
Ordered mesoporous silica materials were prepared under different $\mathrm{pH}$ conditions by using a silicon alkoxide as a silica source and polyion complex (PIC) micelles as the structure-directing agents. PIC micelles were formed by complexation between a weak polyacid-containing double-hydrophilic block copolymer, poly(ethylene oxide)- $b$-poly(acrylic acid) (PEO- $b$-PAA), and a weak polybase, oligochitosan-type polyamine. As both the micellization process and the rate of silica condensation are highly dependent on $\mathrm{pH}$, the properties of silica mesostructures can be modulated by changing the $\mathrm{pH}$ of the reaction medium. Varying the materials synthesis $\mathrm{pH}$ from 4.5 to 7.9 led to 2D-hexagonal, wormlike or lamellar mesostructures, with a varying degree of order. The chemical composition of the as-synthesized hybrid organic/inorganic materials was also found to vary with $\mathrm{pH}$. The structure variations were discussed based on the extent of electrostatic complexing bonds between acrylate and amino functions and on the silica condensation rate as a function of $\mathrm{pH}$.
\end{abstract}

\section{Introduction}

Due to their unique physicochemical properties originating from their uniform pore size and periodically arranged network at the mesoscale, silica-based ordered mesoporous materials (OMMs) have attracted considerable attention in various fields such as adsorption, separation and catalysis. The formation of these mesostructures relies on a supramolecular assembly process between silicic species and surfactants or amphiphilic block copolymers acting as structure directing agents (SDAs) of silica. The assembly process can occur following two different interaction pathways: one is based on an electrostatic charge- 
matching mechanism between the SDA (cationic $\mathrm{S}^{+}$, anionic $\mathrm{S}^{-}$ or protonated neutral $\mathrm{S}^{0}$ denoted as $\mathrm{S}^{0} \mathrm{H}^{+}$) and inorganic species $\left(\mathrm{I}^{+}\right.$or $\left.\mathrm{I}^{-}\right)$interacting either directly or through a mediator species (halide anion $\mathrm{X}^{-}$or alkaline cation $\mathrm{M}^{+}$), [1] while the other one proceeds through an electrically neutral route involving hydrogen bond interactions between neutral amine $\left(\mathrm{S}^{0}\right)[2]$ or poly(ethylene oxide) $\left(\mathrm{N}^{0}\right)$ [3] based SDA and neutral inorganic species $\left(\mathrm{I}^{0}\right)$. Concerning the poly(ethylene oxide) based SDA, it is believed that the nature of the attractive interaction is hydrogen bonding between the silanol groups and the ether oxygen in the PEO block [4,5], as it is the case when PEO adsorbs on a silica surface [6]. It should be noted that the charge-matching pathway requires extreme $\mathrm{pH}$ conditions to produce OMMs, as for the synthesis of the well-known SBA (Santa Barbara Amorphous) and M41S (from Mobil Corporation) materials families, which proceed at $\mathrm{pH}<1$ and $\mathrm{pH}>9$, respectively. On the contrary, the neutral route necessitates less severe $\mathrm{pH}$ conditions, which are much more appropriate for a large-scale material production with controlled environmental, health and safety risks. Among the SDA materials that have been employed, non-ionic block copolymers such as poly(alkylene oxide) triblock copolymers have attracted more attention due to the formation of thermally and mechanically stable materials with larger pore sizes and thicker walls than those obtained with surfactants. This opens up the possibility of easily functionalizing them and tailoring the mesopore arrangement into various ordered mesostructures [7]. This is especially true as long as the material synthesis is conducted under strongly acidic conditions (charge-matching pathway $\left(\mathrm{S}^{0} \mathrm{H}^{+}\right)\left(\mathrm{X}^{-} \mathrm{I}^{+}\right)$) $[4,8]$. In contrast, the first attempts to synthesize materials in quasi neutral solution $(\mathrm{pH}>2)$ using non-ionic block copolymers, which involve weaker interactions between the PEO chains and neutral silicic species, resulted in more disordered framework structures with worm-like mesopore channels of uniform diameter [3], designed as MSU- $X$. It should be mentioned that the reported synthesis protocols made use of synchronous reaction steps involving co-assembly of the template and the inorganic precursor and hydrolysis and condensation of the silica precursor. Bearing this in mind, the lack of a well-defined periodic structure of MSU- $X$ may be imputed to the type of silica precursor generally used, namely alkoxysilanes like tetraethoxysilane (TEOS), whose rate of hydrolysis and condensation varies inversely as a function of $\mathrm{pH}$ [9]. Thus, synthesis at $\mathrm{pH}$ values above the isoelectric point of silica promotes condensation reactions that occur between silica species, which are only partially hydrolyzed, whereas fully hydrolyzed monomeric silica species would be desired for producing mesostructures with optimal structural order. As a matter of fact, using a rapid hydrolyzing alkoxysilane such as tetramethoxysilane (TMOS) that hydrolyses faster than TEOS, Kim et al. evidenced the possibility to produce hexagonally ordered structures from Pluronic P123 up to $\mathrm{pH} 4$. The structural order can even be further extended up to $\mathrm{pH} 9$ in the presence of fluoride ions due to their catalytic activity in hydrolysis reactions [10].

Several synthesis approaches aiming at separating the hydrolysis and the condensation steps were subsequently proposed to produce ordered mesostructured silica materials under mild $\mathrm{pH}$ conditions. Among them the use of sodium silicate as a silica source instead of silicon alkoxide judiciously discards the hydrolysis reactions. Adding silicate directly to a non-ionic block copolymer solution made of acid $[11,12]$ or buffer [1316] media allowed materials with ordered mesopores to be obtained up to $\mathrm{pH}$ 6.5. Interestingly, this relatively inexpensive silica precursor and the rather environmentally friendly synthesis route employed (neutral $\mathrm{pH}$ conditions, low temperature, short synthesis and aging times) open up new opportunities for batch and continuous mode large-scale production of ordered mesoporous silica materials $[17,18]$. Alternatively, the hydrolysis and condensation steps of the more popular silicon alkoxide precursors can be separated following a two-step approach in which the hydrolysis of the alkoxysilane is first performed in acidic medium and the silica condensation step is triggered with the aid of sodium fluoride and/or pH adjustment [19]. Separating the hydrolysis of TEOS from the condensation step enabled highly ordered 2D hexagonal SBA-15-type [20] and cubic $[21,22]$ SBA-16-type materials to be obtained up to $\mathrm{pH} 5$ and $\mathrm{pH} 4-4.5$, respectively.

Since 2008, we have been developing an original route for the synthesis of ordered mesoporous materials based on the use of non-conventional structure-directing agents. Ordered mesoporous silica and organosilica materials were prepared under mild acidic conditions by using polyion complex (PIC) micelles as versatile $\mathrm{pH}$-sensitive structure-directing agents $[23,24]$. This route relies on the use of a weak polyacid double hydrophilic block copolymer (DHBC) able to form polyion complex micelles upon interaction with a weak polybase. We reported that DHBCs such as poly(ethylene oxide)- $b$-poly(acrylic acid) (PEO- $b$-PAA) or poly(ethylene oxide)- $b$-poly(methacrylic acid) (PEO- $b$-PMAA) copolymers, are able to form polyion complex (PIC) micelles upon interaction with weak polybases such as oligochitosan (OC) [25], poly-L-lysine (PLL) [26,27] and aminoglycoside antibiotics [28]. PIC micelles present a core-corona structure, whose core is formed by electrostatic interactions between the two charged blocks (i.e., the PAA and the weak polybase) and the corona is constituted by the neutral PEO block of the DHBC, which ensures the steric stabilization of the assembly in water. In the presence of silica precursors, the hybrid organic-inorganic interface, which is necessary for directing the macroscopic precipitation of the hybrid material, 
can form through an interaction between the PEO neutral block and silicic species via the $\mathrm{N}^{0} / \mathrm{I}^{0}$ pathway, as in the case of SBAtype materials synthesized under acidic conditions, as long as no competing interactions involving silicic species exist. In a previous study, we had shown that when the strength of the organic-inorganic interaction is kept constant (by synthesizing hybrid materials at a fixed $\mathrm{pH}$ ), the material mesostructure can be controlled by varying parameters that alter interactions between the different constituents of the system, such as the molar ratio between the complexing units, the molar ratio between ethylene oxide (EO) units and silica species, and the mass concentration of the reactants in the synthesis medium [26]. In the present paper, we investigate how a simple synthesis parameter, such as the $\mathrm{pH}$ of the reaction medium, which governs not only the extent of the polyion electrostatic complexation but also the silica condensation rate, influences the macrophase separation of the hybrid material and the nature of the mesostructures which are obtained. The variations of the mesostructures and the chemical composition of the corresponding hybrid materials as a function of $\mathrm{pH}$ are reported and discussed.

\section{Experimental Materials}

Poly(ethylene oxide)- $b$-poly(acrylic acid) (PEO- $b$-PAA, $\left.M_{\mathrm{PEO}}=5000 \mathrm{~g} \cdot \mathrm{mol}^{-1}, M_{\mathrm{PAA}}=1420 \mathrm{~g} \cdot \mathrm{mol}^{-1}\right)$ was synthesized by atom transfer radical polymerization (ATRP) according to published procedures [29]. All reactions were carried out in the absence of air using standard Schlenk techniques and vacuumline manipulation. All the chemicals used for the reaction (tertbutyl acrylate $98 \%$, $\alpha$-methoxy- $\omega$-hydroxy-poly(ethylene oxide) with $M_{\mathrm{n}}=5000 \mathrm{~g} \cdot \mathrm{mol}^{-1}, \mathrm{CuBr} 98 \%, 1,1,1,7,10,10$-hexamethyltriethylenetetramine $97 \%$, trifluoroacetic acid $99 \%$, triethylamine 99\%, 2-bromoisobutyryl bromide 98\%, absolute ethanol, toluene $99.8 \%$, THF $99.9 \%$, acetone $99.5 \%$, diethyl ether $99.5 \%$, glacial acetic acid, dichloromethane, pentane, sodium chloride, DOWEX MSC-H resin, neutral alumina 50-200 $\mu \mathrm{m}$ ) were purchased from Sigma-Aldrich and purified when necessary ( $\alpha$-methoxy- $\omega$-hydroxy-poly(ethylene oxide), tert-butyl acrylate, toluene, THF, acetone); the solvents were dried and distilled by routine procedures. Oligochitosan lactate (OC, M < $\left.5000 \mathrm{~g} \cdot \mathrm{mol}^{-1}\right)$, tetraethoxysilane (TEOS), nitric acid $\left(\mathrm{HNO}_{3}\right)$ and sodium hydroxide $(\mathrm{NaOH})$ were purchased from Aldrich and used as received.

\section{Chemical composition of the oligochitosan}

A detailed characterization of the commercial oligochitosan (OC) was undertaken in order to determine the chemical composition of the repetitive unit necessary to fix the quantity of nitrogen per acrylic acid (N/AA ratio) used in the materials synthesis. The deacetylation degree ( $\mathrm{DD}=83 \pm 5 \%$ ) was determined by solid state ${ }^{15} \mathrm{~N}$ NMR using a Varian VNMRS 600 spectrometer operating at $5 \mathrm{kHz}$ using cross-polarization magicangle spinning conditions [30]. The DD was calculated from the integration of the amide $(\delta=101 \mathrm{ppm})$ and amine $(10 \mathrm{ppm})$ peaks using the following formula:

$$
\% \mathrm{DD}=\frac{I_{\mathrm{N} \text {-amine }}}{I_{\mathrm{N} \text {-amine }}+I_{\mathrm{N} \text {-amide }}} * 100 .
$$

Note that a similar DD was obtained from liquid ${ }^{1} \mathrm{H}$ NMR data recorded on a Bruker $400 \mathrm{MHz}$ spectrometer using the method reported by Trombotto et al. [30].

The quantity of lactate/lactic acid present in the sample was calculated from the liquid ${ }^{1} \mathrm{H}$ NMR spectrum recorded in $\mathrm{D}_{2} \mathrm{O}$. The amount of water was deduced from elemental analysis. The molar composition of the repetitive unit constituting the oligochitosan was then: $\mathrm{H}-\left(\mathrm{C}_{6} \mathrm{H}_{11} \mathrm{O}_{4} \mathrm{~N}\right)_{0.83}\left(\mathrm{C}_{8} \mathrm{H}_{13} \mathrm{O}_{5} \mathrm{~N}\right)_{0.17}-\mathrm{OH}$, $1.31\left(\mathrm{C}_{3} \mathrm{H}_{6} \mathrm{O}_{3}\right), 0.09\left(\mathrm{H}_{2} \mathrm{O}\right)$, where $\mathrm{C}_{6} \mathrm{H}_{11} \mathrm{O}_{4} \mathrm{~N}$ represents the deacetylated unit, $\mathrm{C}_{8} \mathrm{H}_{13} \mathrm{O}_{5} \mathrm{~N}$ the acetylated unit and $\mathrm{C}_{3} \mathrm{H}_{6} \mathrm{O}_{3}$ the lactate ion.

\section{Preparation of mesostructured silica materials}

Mesostructured hybrid silica materials were prepared following a one-pot synthesis approach. The concentration of OC and TEOS were fixed with respect to the number of acrylic acid (AA) and ethylene oxide (EO) units of the PEO- $b$-PAA, using a molar ratio of 0.8 nitrogen per $\mathrm{AA}(\mathrm{N} / \mathrm{AA}=0.8)$ and 1 silicon per $\mathrm{EO}(\mathrm{EO} / \mathrm{Si}=1)$. The final concentration of the reaction medium was set at 3.9 wt $\%$ of PEO- $b$-PAA, unless otherwise specified. Typically, TEOS $(0.397 \mathrm{~mL})$ was added into a homogeneous aqueous solution $(2.0 \mathrm{~mL})$ containing PEO- $b$-PAA $(100 \mathrm{mg})$ and $\mathrm{OC}(77.5 \mathrm{mg})$ and the $\mathrm{pH}$ of the reaction medium was adjusted to 2 using $\mathrm{HNO}_{3}\left(2 \mathrm{~mol} \cdot \mathrm{L}^{-1}\right)$. After completion of TEOS hydrolysis (about $40 \mathrm{~min}$ under vigorous magnetic stirring), the $\mathrm{pH}$ was rapidly increased to a fixed and well-defined value (ranging from 4 to 7.9 ) by adding a small amount of an aqueous $\mathrm{NaOH}$ solution $\left(3 \mathrm{~mol} \cdot \mathrm{L}^{-1}\right)$. This results in macroscopic precipitation, which occurs more or less rapidly according to the $\mathrm{pH}$ value ( $3 \mathrm{~min}$ at $\mathrm{pH} 5$ and $0.5 \mathrm{~min}$ at $\mathrm{pH} 7.9$ ). The mixture was stirred slowly for 24 additional hours at $30^{\circ} \mathrm{C}$. The precipitate was then recovered by centrifugation and air-dried at $40{ }^{\circ} \mathrm{C}$ for 48 hours. For characterization purposes, the as-synthesized hybrid materials were calcined under air flow from room temperature to $550{ }^{\circ} \mathrm{C}$ at a heating rate of $2{ }^{\circ} \mathrm{C} \cdot \mathrm{min}^{-1}$ and then maintained at $550^{\circ} \mathrm{C}$ for 8 hours.

\section{Characterization techniques}

The formation of polyion complex (PIC) micelles as a function of $\mathrm{pH}(3<\mathrm{pH}<10)$ was studied by dynamic light scattering (DLS) experiments at $25 \pm 1^{\circ} \mathrm{C}$ using a Malvern 4800 spectrogoniometer (Malvern Instruments, UK) equipped with a $50 \mathrm{~mW}$ 
laser operating at $532 \mathrm{~nm}$. The scattered light was collected at an angle of $90^{\circ}$. The static scattered light intensities were corrected from the pinhole size and normalized with respect to a Rayleigh scattered reference (toluene). The intensity autocorrelation function was fitted using the CONTIN algorithm for the determination of the volume-averaged hydrodynamic diameters $\left(D_{\mathrm{hv}}\right)$; the polydispersity index (PDI) values were obtained from the cumulant method.

The chemical composition of the hybrid materials was calculated by combining thermogravimetric analysis (TGA), which allows quantifying the silica content, and $\mathrm{N}$ and $\mathrm{C}$ elemental analyses (EA), which allow determining the quantity of $\mathrm{OC}$ and PEO- $b$-PAA in the material. The results were expressed as $\mathrm{N} / \mathrm{AA}$ and $\mathrm{EO} / \mathrm{Si}$ ratios given with $\pm 5 \%$ relative error. TGA was performed on a Perkin Elmer STA 6000 instrument at a heating rate of $10{ }^{\circ} \mathrm{C} \cdot \mathrm{min}^{-1}$ under an air flow $\left(20 \mathrm{~mL} \cdot \mathrm{min}^{-1}\right)$ up to $900{ }^{\circ} \mathrm{C}$. The mass percentage of silica $\left(\% \operatorname{mass}\left(\mathrm{SiO}_{2}\right)\right)$ was calculated from the residual mass at $900{ }^{\circ} \mathrm{C}$. The EA of the hybrid materials was performed on an Interscience Flash EA 1112 series (Thermo Finnigan) instrument. The value of the mass percentage of OC (\% mass (OC)) in the hybrid materials, $\% \mathrm{~N}$, which in turn was used to calculate the DHBC weight percentage ( $\%$ mass $(\mathrm{DHBC})), \% \mathrm{C}$, can be calculated according to the following equations:

$$
\begin{gathered}
\% \mathrm{~N}=\% \operatorname{mass}(\mathrm{OC}) \times \% \operatorname{mass}(\mathrm{N} / \mathrm{OC}) \\
\% \mathrm{C}=(\% \operatorname{mass}(\mathrm{OC}) \times \% \operatorname{mass}(\mathrm{C} / \mathrm{OC})) \\
+(\% \operatorname{mass}(\mathrm{DHBC}) \times \% \operatorname{mass}(\mathrm{C} / \mathrm{DHBC}))
\end{gathered}
$$

where \% mass (N/OC), \% mass (C/OC) and \% mass $(\mathrm{C} / \mathrm{DHBC})$, respectively stand for the mass content of $\mathrm{N}$ and $\mathrm{C}$ in $\mathrm{OC}$ and of $\mathrm{C}$ in the DHBC.

The degree of condensation $(D)$ of the as-synthesized silica network was determined by ${ }^{29} \mathrm{Si}$ MAS-NMR spectroscopy using a Varian VNMRS 300MHz spectrometer. The typical $\mathrm{Q}_{4}$, $\mathrm{Q}_{3}$ and $\mathrm{Q}_{2}$ signals appearing respectively at $-110 \mathrm{ppm}\left(\mathrm{SiO}_{2}\right)$, $-100 \mathrm{ppm}\left(\mathrm{SiO}_{3 / 2}\right)$ and $-90 \mathrm{ppm}\left(\mathrm{SiO}(\mathrm{OH})_{2}\right)$ were deconvoluted, and the areas were used for calculating $D$.

The textural properties of the materials were determined from the nitrogen sorption isotherms recorded at $77 \mathrm{~K}$ using a Micrometics Tristar 3000 apparatus. Prior to analysis, the samples were outgassed for $14 \mathrm{~h}$ under vacuum ( $0.08 \mathrm{mbar})$ at $250{ }^{\circ} \mathrm{C}$ for calcined materials and at $45{ }^{\circ} \mathrm{C}$ for hybrid materials. The surface area $\left(S_{\mathrm{BET}}\right)$ was determined from the Brunauer-Emmett-Teller (BET) analysis in the relative pressure range corresponding to $p / p^{0}<0.4$ and assuming a surface coverage of $13.5 \AA^{2}$ per nitrogen molecule [31,32]. The mesopore volume was calculated using the $\alpha_{S}$ method; the diameter of cylindrical pores was determined from the adsorption branch using the nonlocal density functional theory (NLDFT) model [32] and the width of slit-shaped pores was estimated from the desorption branch using the method of Broekhoff and de Boer [33].

The structural properties were studied by small angle X-ray scattering (SAXS) and electron microscopy. SAXS measurements were performed in transmission mode on an in-house setup at the Laboratoire Charles Coulomb (Université Montpellier, France) using a high brightness, low power X-ray tube $(\lambda=1.5418 \AA)$. All the intensities were corrected from transmission and empty capillary. Transmission electron microscopy (TEM) images were acquired on microtomed samples (slices of $\approx 70 \mathrm{~nm}$ thickness) with a JEOL 1200 EX II instrument operating at $120 \mathrm{kV}$. Material characterization by scanning electron microscopy (SEM) was done on a HITACHI S4800 (FEG-HR) apparatus operating at $5 \mathrm{kV}$.

\section{Results and Discussion \\ Formation of polyion complex micelles}

The double hydrophilic block copolymer (DHBC) used in this study is a poly(ethylene oxide)- $b$-poly(acrylic acid) copolymer $\left(\mathrm{PEO}-b\right.$-PAA, $M_{\mathrm{PEO}}=5000 \mathrm{~g} \cdot \mathrm{mol}^{-1}, M_{\mathrm{PAA}}=1420 \mathrm{~g} \cdot \mathrm{mol}^{-1}$ ) able to complex oligochitosan (OC) via electrostatic interactions in a suitable $\mathrm{pH}$ range where both the DHBC and OC are charged. The formation of polyion complex (PIC) micelles is evidenced by an increase of the scattered light intensity due to the formation of macromolecular assemblies. Figure 1 shows the variation of the scattered light intensity of mixtures of PEO$b$-PAA and $\mathrm{OC}$ as a function of $\mathrm{pH}(2<\mathrm{pH}<10)$. PEO- $b$-PAA/ OC PIC micelles are obtained in the 4.5-7.2 $\mathrm{pH}$ range and are characterized by a mean hydrodynamic diameter $\left(D_{\mathrm{hv}}\right)$ of $\approx 25 \mathrm{~nm}$.

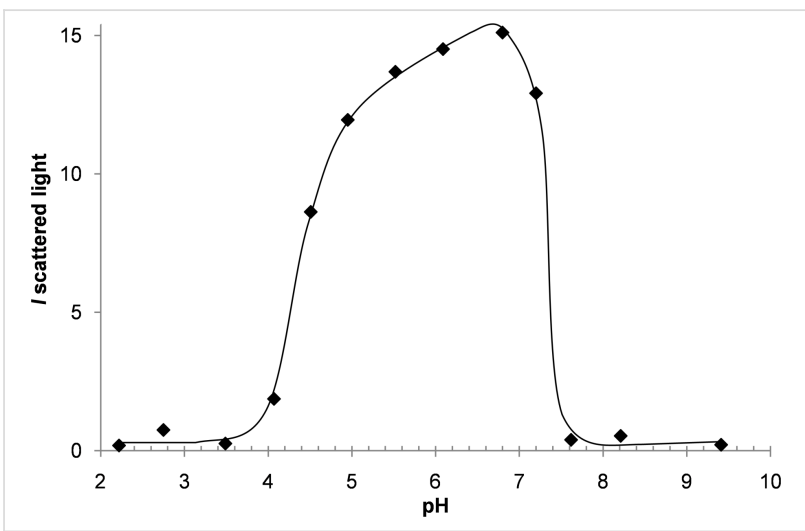

Figure 1: Variation of the scattered light intensity of PEO- $b-\mathrm{PAA} / \mathrm{OC}$ mixtures $\left([A A]=0.01 \mathrm{~mol} \cdot \mathrm{L}^{-1}, \mathrm{~N} / \mathrm{AA}=0.8\right)$ as a function of $\mathrm{pH}$. 


\section{Structure characterization of the calcined materials}

Hybrid organic-inorganic materials were synthesized following a two-step approach. First, the reactants (TEOS, PEO- $b$-PAA and $\mathrm{OC}$ ) were mixed together at low $\mathrm{pH}(\mathrm{pH} 2)$ until a homogeneous solution of hydrolyzed silicic species, PEO- $b$-PAA and $\mathrm{OC}$ was obtained. Note that at $\mathrm{pH} 2$ the silica structure-directing agent (SDA) constituted of PEO- $b$-PAA/OC PIC micelles is not formed (see Figure 1) due to the lack of favorable electrostatic interactions, whereas the organic-inorganic interface is thought to be formed by the $\mathrm{N}^{0} / \mathrm{I}^{0}$ pathway. Then the $\mathrm{pH}$ of the reaction medium was increased in order to promote both formation of PIC micelles and condensation of silica oligomers, in- ducing sudden macroscopic precipitation in less than $3 \mathrm{~min}$. Two different mass concentrations of the reaction medium, expressed by the wt $\%$ of DHBC, were used. The 3.9 wt $\%$ concentration was aimed at evaluating the influence of the $\mathrm{pH}$ on the texture, structure and chemical composition of the obtained materials by carefully screening the $4-7.9 \mathrm{pH}$ domain, whereas the $1.9 \mathrm{wt} \%$ concentration was used at only two strategic $\mathrm{pH}$ values ( $\mathrm{pH} 4.5$ and 6.5 , see thereafter) with the aim of confirming the general effects observed at $3.9 \mathrm{wt} \%$. After calcination $\left(8 \mathrm{~h}\right.$ at $\left.550{ }^{\circ} \mathrm{C}\right)$, the materials synthesized under the various $\mathrm{pH}$ conditions presented an organization at the mesoscale as clearly evidenced on the TEM images of Figure 2a and Figure S1 in Supporting Information File 1, except in the
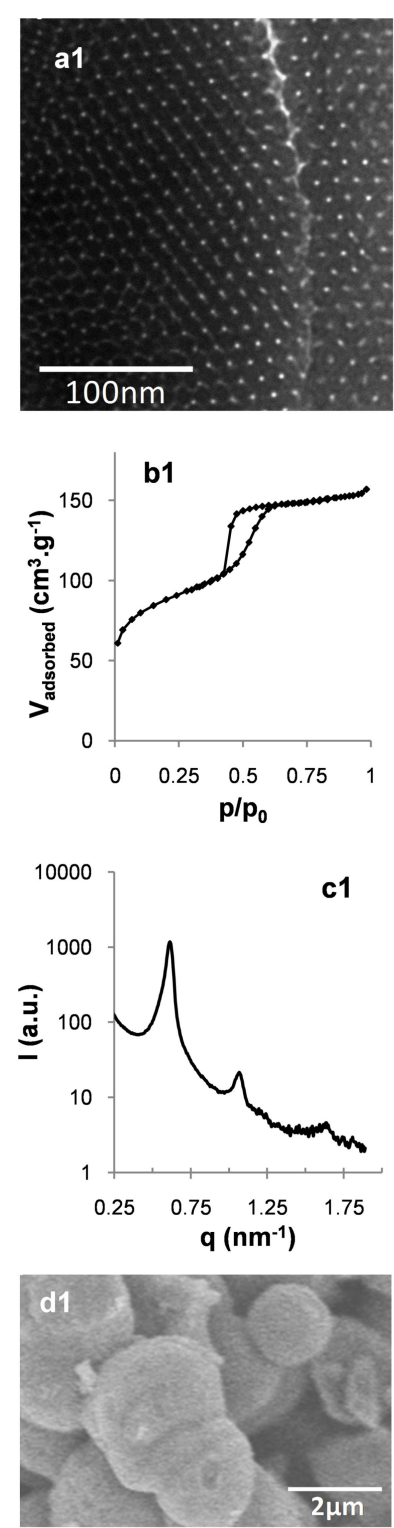
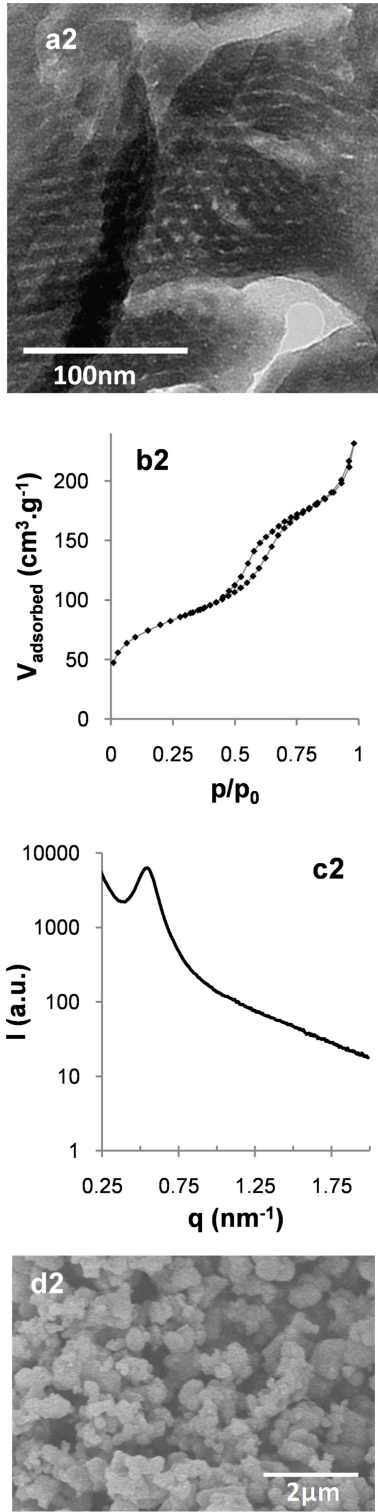
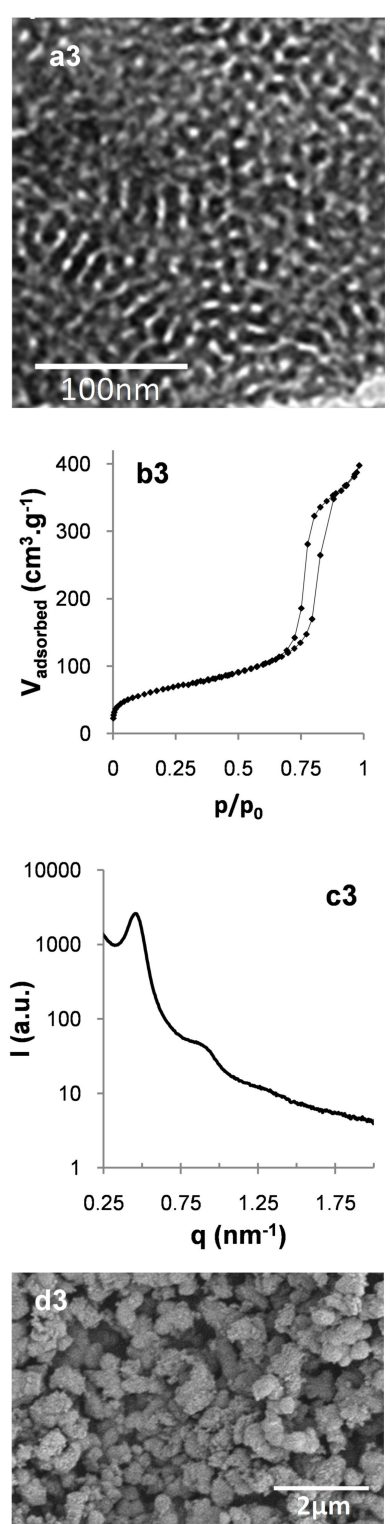

Figure 2: TEM micrographs (a), $\mathrm{N}_{2}$ adsorption/desorption isotherms (b), SAXS patterns (c) and SEM images (d) of the calcined materials synthesized with $3.9 \mathrm{wt} \% \mathrm{DHBC}$ at $\mathrm{pH} 4.5$ (d1), 6.5 (d2) and 7.9 (d3). 
case of $\mathrm{pH} 4$ where a moderately porous silica material $\left(V_{\text {meso }}=\right.$ $\left.0.11 \mathrm{~g} \cdot \mathrm{cm}^{3}\right)$ with non-ordered small mesopores $\left(d_{\text {pore }}=3.9 \mathrm{~nm}\right)$ was obtained (see TEM in Figure S1, Supporting Information File 1). At pH 4, only very few PIC micelles were formed, as evidenced by the very low light scattered intensity (Figure 1); it is then obvious that the silicic species induced precipitation of a long range organized hybrid PIC-based mesostructure, which requires a sufficient amount of micelles, cannot occur. Interestingly, at the highest $\mathrm{pH}$ values ( $\mathrm{pH} 7.4$ and 7.9), ordered mesostructures were obtained. This could appear as a surprising result since these two $\mathrm{pH}$ values are outside of the micellization $\mathrm{pH}$ range (Figure 1), as determined in the absence of silica precursors. The formation of mesostructures at a $\mathrm{pH}$ above $\mathrm{pH} 7$ can be understood by considering (1) the fact that the adjustment of $\mathrm{pH}$ at its final value is done by a progressive addition of a base solution up to the final $\mathrm{pH}$, going inevitably through the micellization $\mathrm{pH}$ range where the structure-directing agent forms, and (2) the fact that the silica condensation rate regularly increases above $\mathrm{pH} 2$ favoring the formation of the hybrid structure. These two features lead to the precipitation of the hybrid mesostructures at a $\mathrm{pH}$ well below the final targeted synthesis $\mathrm{pH}$. These considerations will be further developed when discussing the silica material structuring below. At intermediate $\mathrm{pH}$, but within the $\mathrm{pH}$ domain where micelles formed (Figure 1), the structure of the mesopores is 2D-hexagonal in the 4.5-5.5 pH range and a mixture of wormlike/lamellar at pH 5.5-6.9 (Figure S1, Supporting Information File 1). The mesopore volume increases from $V_{\text {meso }}=0.17 \mathrm{~cm}^{3} \cdot \mathrm{g}^{-1}$ at $\mathrm{pH} 4.5$ to $0.32 \mathrm{~cm}^{3} \cdot \mathrm{g}^{-1}$ at $\mathrm{pH} 6.9$, in accordance with the pore diameter change $\left(d_{\text {pore }}=5.0 \mathrm{~nm}\right.$ at $\mathrm{pH} 4.5$ and $6.4 \mathrm{~nm}$ at pH 6.9, see Table 1). Similarly, the lattice spacing value, $d_{0}$, of the calcined materials shows a slight tendency to increase (Table 1$)$. The $d_{\text {pore }} / d_{0}$ ratio is then almost constant $\left(d_{\text {pore }} / d_{0} \approx 0.50\right)$, indicating that the mesostructure formation mechanism is similar within that $\mathrm{pH}$ range. Figure 3 helps to highlight the changes in the mesoporous volume (Figure $3 \mathrm{a}$ ) and pore diameter (Figure $3 \mathrm{~b}$ ) observed upon synthesis of the materials on the whole $\mathrm{pH}$ range studied $(4.5 \leq \mathrm{pH}<7.9)$. It evidences three main $\mathrm{pH}$ domains $(4.5 \leq \mathrm{pH}<5.5,5.5 \leq \mathrm{pH} \leq 6.9$ and $7.4 \leq \mathrm{pH} \leq 7.9$ ), for which the porous properties exhibit

Table 1: Textural and structural properties of the calcined materials synthesized at $3.9 \mathrm{wt} \%$ DHBC: lattice parameter $\left(d_{0}\right)$, pore diameter $\left(d_{\text {pore }}\right)$, full width at half maximum of the pore size distribution $\left(\Delta d_{1 / 2}\right)$, mesoporous volume $\left(V_{\text {meso }}\right)$, external surface area $\left(S_{\text {ext }}\right)$ of the particles and particle size $\left(d_{\text {particle }}\right)$.

\begin{tabular}{|c|c|c|c|c|c|c|c|c|c|}
\hline $\mathrm{pH}$ & 4.5 & 4.9 & 5.3 & 5.5 & 6.0 & 6.5 & 6.9 & 7.4 & 7.9 \\
\hline$d_{0}(\mathrm{~nm})$ & 10.2 & 11.1 & 10.6 & 11.6 & 11.9 & 11.5 & 11.3 & 13.5 & 13.8 \\
\hline $\begin{array}{l}d_{\text {pore }}(\mathrm{nm}) \\
\Delta d_{1 / 2}(\mathrm{~nm})\end{array}$ & $\begin{array}{l}5.0 \\
1.0\end{array}$ & $\begin{array}{l}5.4 \\
1.0\end{array}$ & $\begin{array}{l}5.4 \\
1.2\end{array}$ & $\begin{array}{l}5.7 \\
1.6\end{array}$ & $\begin{array}{l}5.7 \\
1.7\end{array}$ & $\begin{array}{l}5.9^{a} \\
1.7\end{array}$ & $\begin{array}{l}6.4^{a} \\
2.3\end{array}$ & $\begin{array}{l}9.2 \\
3.0\end{array}$ & $\begin{array}{l}10.2 \\
2.9\end{array}$ \\
\hline$V_{\text {meso }}\left(\mathrm{cm}^{3} \cdot \mathrm{g}^{-1}\right)$ & 0.17 & 0.19 & 0.19 & 0.17 & 0.23 & 0.25 & 0.32 & 0.53 & 0.55 \\
\hline$S_{\text {ext }}\left(m^{2} \cdot g^{-1}\right)$ & 13 & 15 & 27 & 39 & 73 & 125 & 123 & 124 & 130 \\
\hline$d_{\text {particle }}(\mathrm{nm})$ & 2300 & 1200 & 900 & 700 & 600 & 290 & 380 & 310 & 220 \\
\hline
\end{tabular}

amean pore diameter.
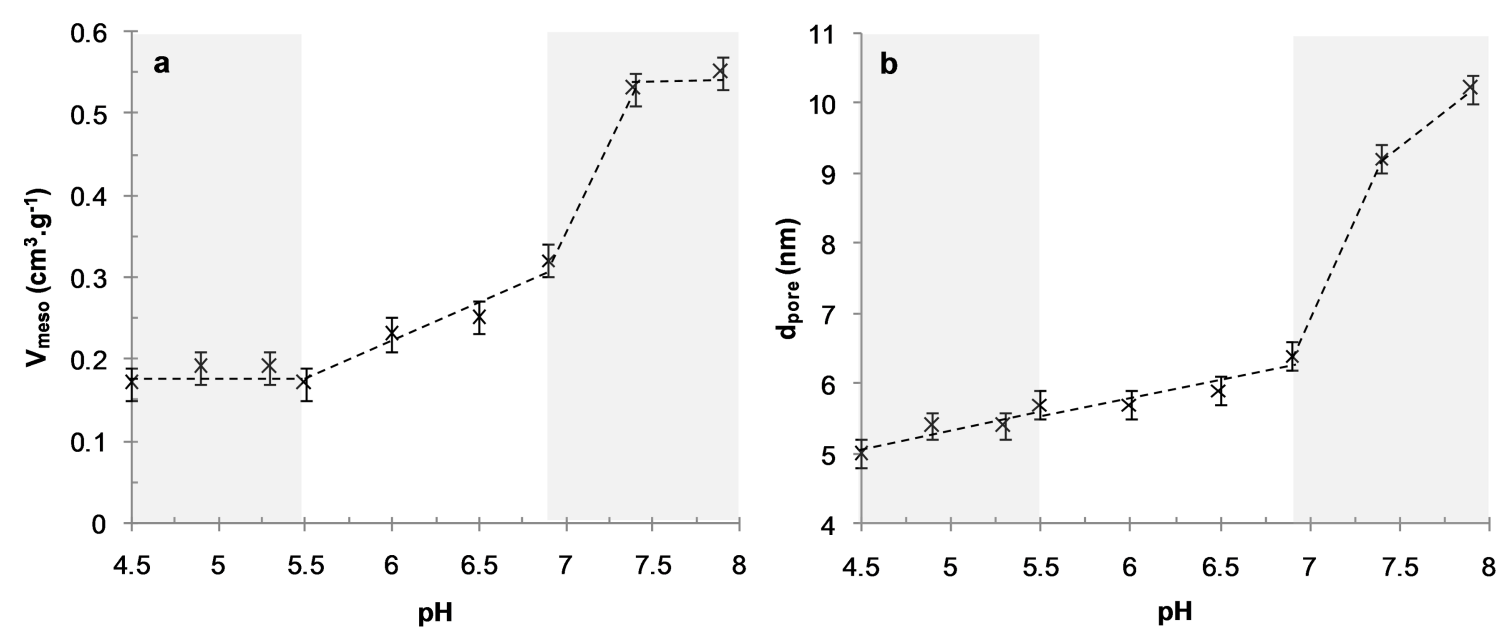

Figure 3: Mesopore volume (a) and pore diameter (b) of the calcined materials synthesized at $3.9 \mathrm{wt} \% \mathrm{DHBC}$ at various values of $\mathrm{pH}$. 
some common features together with the typical mesostructures of the materials illustrated on Figure 2a, which evolved from long-range ordered 2D-hexagonal $(4.5 \leq \mathrm{pH}<5.5)$ to a lessordered worm-like/lamellar mixture $(5.5 \leq \mathrm{pH} \leq 6.9)$ to a shortrange ordered honeycomb-like arrangement of cylindrical mesopores. For the sake of clarity, in the following, the influence of the synthesis $\mathrm{pH}$ on the material formation will be discussed by distinguishing these three main $\mathrm{pH}$ domains.

In the most acidic domain $(4.5 \leq \mathrm{pH}<5.5)$, agglomerated spherical particles with a well-defined 2D hexagonal ordered mesostructure were obtained, as evidenced by TEM images (Figure 2a and Figure S1 in Supporting Information File 1). This mesostructure is confirmed by SAXS profiles (Figure $2 \mathrm{c}$ and Figure S2a in Supporting Information File 1), which exhibit up to four distinct scattering peaks whose relative positions respective to the first one appear at a ratio of $1: \sqrt{ } 3: \sqrt{ } 4: \sqrt{ } 7$, corresponding to the (100), (110), (200) and (210) diffraction planes of long-range ordered hexagonally packed cylindrical structures (Table S1a, Supporting Information File 1). It should also be mentioned that the $\mathrm{N}_{2}$ sorption isotherms (Figure S3 in Supporting Information File 1) exhibited the typical type-IV shape of mesoporous materials with H1-like hysteresis loop (IUPAC classification [34]) showing capillary condensation at a relative
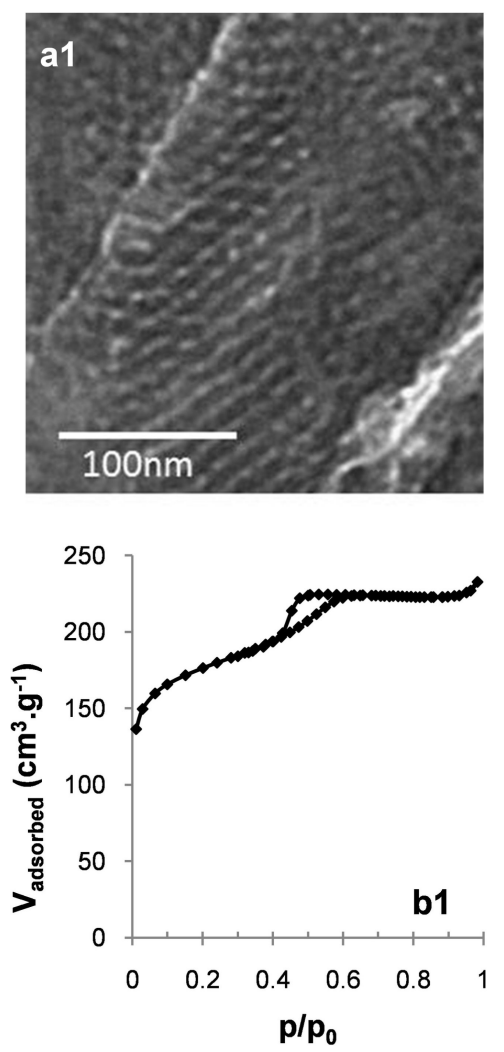

pressure $p / p_{0}$ ranging from 0.42 to 0.70 . This indicates that the structural mesoporosity presents a cylindrical pore geometry with a high degree of pore size uniformity. This is confirmed by the narrow pore size distribution (PSD) calculated from the adsorption branch by the NLDFT method (Figure S3 in Supporting Information File 1). Within that $\mathrm{pH}$ range, the mean pore diameter $\left(d_{\text {pore }}\right)$ and mesopore volume $\left(V_{\text {meso }}\right)$ slightly increase with $\mathrm{pH}$ (Table 1). When the synthesis was performed at 1.9 wt $\%$ of DHBC and $\mathrm{pH} 4.5$, a material with a mixed mesostructure consisting of lamellar domains coexisting with some 2D-hexagonal domains was obtained, as evidenced both by TEM images (Figure 4a) and SAXS profiles (Figure S2d in Supporting Information File 1), which exhibit two major diffraction peaks ascribed to the (100), and (200) planes of the lamellar/hexagonal structure and a weaker peak that could correspond to the (110) plane of the hexagonal structure. The nitrogen sorption isotherm (Figure 4b) exhibits a very low adsorption step, in good agreement with this mixture of mesostructures.

When further increasing the $\mathrm{pH}(5.5 \leq \mathrm{pH} \leq 6.9)$, the wellordered hexagonal mesostructure progressively evolved towards less-ordered structures containing domains with wormhole-like mesopores coexisting with domains of slit-shaped pores resem-
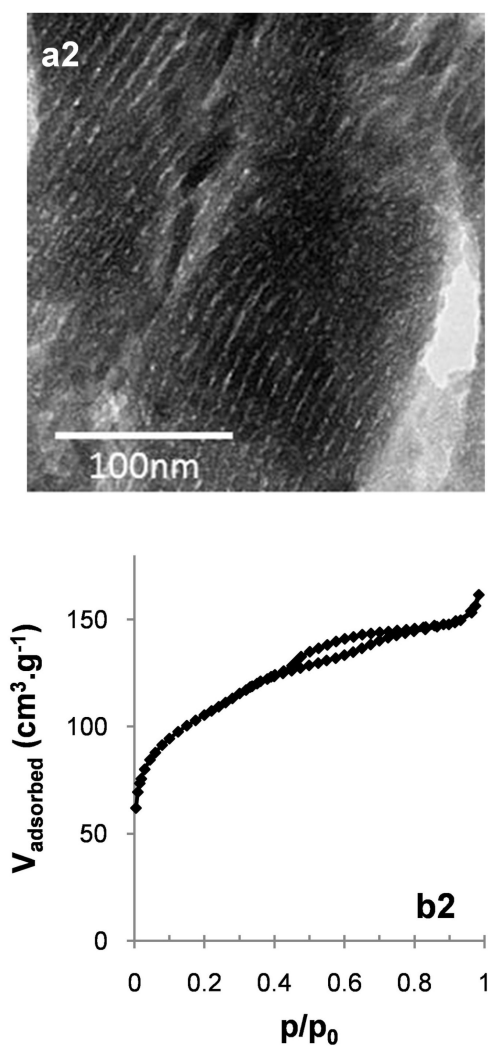

Figure 4: TEM micrographs (a) and $\mathrm{N}_{2}$ adsorption/desorption isotherms (b) of the calcined materials prepared at 1.9 wt $\%$ DHBC at pH 4.5 (b1) and 6.5 (b2). 
bling short-range lamellar structure. Such lamellar domains appeared first (from pH 5.5) on the edge of the particles (see TEM images on Figure $\mathrm{S} 1$ in Supporting Information File 1). At $\mathrm{pH}$ 6.9, almost no hexagonal mesostructure was visible on TEM images. Moreover, the correlation peaks of the SAXS patterns broadened upon $\mathrm{pH}$ increase and their number decreased until a single peak was observed for materials synthesized at $\mathrm{pH} 6.9$ (Table S1a and Figure S2 in Supporting Information File 1). This is in accordance with the loss of long range-ordered hexagonal structure, as observed in TEM images. In the sorption isotherms, the sharp adsorption step assigned to mesopore filling in the hexagonal materials becomes less pronounced, and the hysteresis loop extends on a wider partial pressure range, in agreement with the presence of lamellar domains coexisting with wormhole pore morphologies. The increase of $\mathrm{pH}$ from 5.5 to 6.9 resulted in a size pore increase with broadening PSD until pH 6 (Table 1), then to the appearance of a bimodal distribution with $d_{\text {pore }}=5.7$ and $7.2 \mathrm{~nm}$, with the fraction of the larger mesopores increasing with $\mathrm{pH}$ (from $12 \%$ to $48 \%$ ). Accordingly, the mesopore volume increased within that $\mathrm{pH}$ range. Such observations reveal an increase of the mean radius of curvature of the mesostructure as a function of $\mathrm{pH}$ up to 6.9. Such an influence of the solution $\mathrm{pH}$ on the variation of mesostructure and mesopore size has also been reported with non-ionic surfactants/copolymers $[11,20,35,36]$ and ionic cetyltrimethylammonium. [37] The up-curvature observed at $p / p^{0}>0.85$ on the $5.5 \leq \mathrm{pH} \leq 6.9$ isotherms (Figure $\mathrm{S} 3$ in Supporting Information File 1) revealed an interparticle porosity, which is consistent with the small size of the silica particles as observed on SEM images (Figure S4 in Supporting Information File 1). As reported in Table 1, the mean particle size decreases from about 700 to $380 \mathrm{~nm}$ in the considered $\mathrm{pH}$ range. When the material synthesis was performed at a lower mass concentration (1.9 wt \% of DHBC) and at $\mathrm{pH} 6.5$, the material presented a well-defined lamellar mesostructure, which survived the removal of the SDA by calcination, as revealed by the TEM image of Figure $4 \mathrm{a}$. The $\mathrm{N}_{2}$ sorption isotherm (Figure $4 \mathrm{~b}$ ) exhibited the classical H3-like hysteresis loop expected for such a mesostructure, with a mesoporous volume of $0.17 \mathrm{~cm}^{3} \cdot \mathrm{g}^{-1}$. A pore thickness of $3 \mathrm{~nm}$ was calculated using the Broekhof and De Boer method from the relative pressure at which complete capillary condensation took place. [33].

The materials prepared at higher $\mathrm{pH}(\mathrm{pH} 7.4$ and 7.9) exhibited a relatively well-ordered pore arrangement, whose mesostructure was however difficult to identify (Figure 2a and Figure S1 in Supporting Information File 1). Nonetheless, some insights can be gathered from TEM, SAXS profiles and $\mathrm{N}_{2}$-adsorption/ desorption data. Up to three scattering peaks with interplanar spacing ratios of 1:2:3 were revealed by SAXS for the material synthesized at pH 7.9 (Figure 2c and Table S1a in Supporting
Information File 1), corresponding either to a lamellar structure or to a hexagonal one with some of the diffraction planes masked under broaden peaks. Let us add that the sorption isotherm did not exhibit the characteristic H3 hysteresis loops of mesoporous structures with slit-like pores, but rather the typical H1 type of cylindrical pore geometry. We thus propose that the mesostructures obtained at $\mathrm{pH}>7$ correspond to an hexagonal arrangement of cylindrical pores organized on very short distances that would account both for the TEM observation and SAXS data. Note that the pores of those materials are particularly large $\left(d_{\text {pore }}=9.2\right.$ and $10.2 \mathrm{~nm}$ at $\mathrm{pH} 7.4$ and 7.9, respectively) compared to the mesopores obtained at lower $\mathrm{pH}$. At $\mathrm{pH} 7.9$, the pore diameter is about twice that of the material obtained at $\mathrm{pH} 4.5\left(d_{\text {pore }}=5.0 \mathrm{~nm}\right)$. This pore diameter increase is accompanied by a significant increase of the d-spacing value $\left(d_{0}=13.8 \mathrm{~nm}\right.$ at $\mathrm{pH} 7.9$, Table 1$)$, compared to the almost constant value obtained between $\mathrm{pH} 4.5$ and $\mathrm{pH} 6.9$ $\left(d_{0}=11.3 \pm 0.7 \mathrm{~nm}\right)$.

The $\mathrm{pH}$ increase also affected the size of the obtained primary spherical particles (see SEM images on Figure 2d and Figure S4 in Supporting Information File 1), which gradually decreased from several micrometers at low $\mathrm{pH}(2300 \mathrm{~nm}$ at $\mathrm{pH} 4.5)$ to a few hundred nanometers above $\mathrm{pH} 7(220 \mathrm{~nm}$ at $\mathrm{pH} 7.9$, Table 1). The external surface area of the particles, as measured by BET analysis, consistently increases within that $\mathrm{pH}$ range (Table 1). Similar particle size reduction upon $\mathrm{pH}$ increase was reported using polyethylene oxide based surfactants [38,39] as SDA of silica; it was ascribed to an increase of the polycondensation rate of silicic species with $\mathrm{pH}$ favoring fast nucleation of small flocs of surfactant and silica [40]. As emphasized by Berggren and Palmqvist [35], these small flocs further grow until reaching a final size that depends on the electrostatic stabilization provided by the $\mathrm{pH}$-dependent negative charge of silica.

\section{Chemical composition of the hybrid materials and formation mechanism of mesostructures}

The chemical composition of the as-synthesized hybrid materials was determined in order to understand how the $\mathrm{pH}$ of the reaction medium influences the interactions between the various constituents of the system and the subsequent mesostructures. The three main interactions to be considered are: the electrostatic interaction involved in the polyion complex formation between amine units (related to $\mathrm{N}$ atoms in $\mathrm{OC}$ ) and acrylic acid units (AA in the DHBC), the hydrogen bond interaction ensuring the formation of the hybrid organic-inorganic interface between the ether oxygen (EO) of the PEO and the silica species ( $\mathrm{Si}$ ), and the self-condensation of silica species. The two molar ratios N/AA and $\mathrm{EO} / \mathrm{Si}$, respectively indicative of the extent of electrostatic complexation and hydrogen bonding, were determined from the chemical mass compositions of 
DHBC (wt \% DHBC), oligochitosan (OC) (wt \% OC) and silica (wt $\% \mathrm{SiO}_{2}$ ) obtained by elemental analysis and thermogravimetric data after drying of the hybrid materials. The silica condensation degree $(D)$ was quantified by ${ }^{29} \mathrm{Si}$ MAS NMR spectroscopy. Table 2 gathers the data related to the compositions of the materials expressed in weight percentages and mg (organics) per gram of $\mathrm{SiO}_{2}$. Figure 5 shows the N/AA and EO/Si ratio variations in the materials as a function of $\mathrm{pH}$.

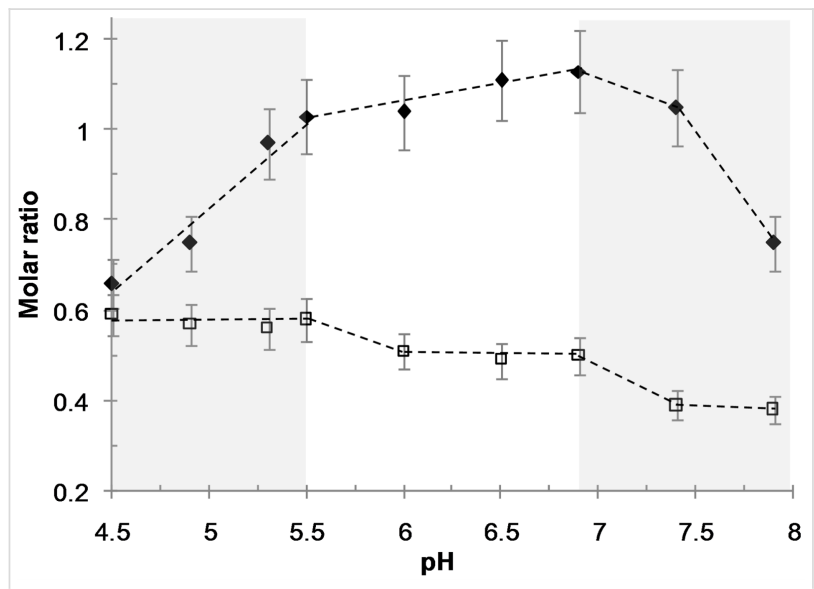

Figure 5: Molar ratio N/AA (filled triangles) and EO/Si (open squares) of the hybrid materials synthesized at $3.9 \mathrm{wt} \% \mathrm{DHBC}$ as a function of $\mathrm{pH}$.

For all $\mathrm{pH}$ values of the reaction medium, the materials present a high silica content $\left(\mathrm{SiO}_{2}\right.$ wt $\%>50 \%$, associated with high silica yield above $80 \%$ ) and a highly condensed inorganic network $(D>86 \%)$. As the $\mathrm{pH}$ increased, the degree of condensation rose (from $D=86 \%$ at $\mathrm{pH} 4.5$ to $91.5 \%$ at $\mathrm{pH} 7.4$ ), in agreement with the $\mathrm{pH}$-dependent condensation rate of silica. The amount of PEO- $b$-PAA incorporated in the materials was relatively high and the variation depends on the $\mathrm{pH}$ domain already discussed above. At $4.5 \leq \mathrm{pH}<5.5$, the DHBC content was almost constant (average $540 \pm 15 \mathrm{mg} \cdot \mathrm{g}_{\mathrm{SiO} 2}{ }^{-1}$ ), and it slightly decreased between pH 5.5 and $6.9\left(468 \mathrm{mg} \cdot \mathrm{g}_{\mathrm{SiO} 2}{ }^{-1}\right.$ at $\mathrm{pH}$ 6.9) and decreased to a higher extent above $\mathrm{pH} 7.4$ where it reached a plateau (average $365 \pm 5 \mathrm{mg} \cdot \mathrm{gSiO}^{-1}$ for $\mathrm{pH} \geq 7.4$ ). The OC content in the materials was much smaller than the DHBC amounts. The OC content relative to silica varies nonmonotonically with $\mathrm{pH}$ : it increases from $\mathrm{pH} 4.5$ to $\mathrm{pH} 5.3$ (from 211 to $299 \mathrm{mg} \cdot \mathrm{g}_{\mathrm{SiO} 2}{ }^{-1}$, respectively), and remained constant up to $\mathrm{pH} 6.9$, and decreased strongly in the highest $\mathrm{pH}$ range to reach $157 \mathrm{mg} \cdot \mathrm{g}_{\mathrm{SiO} 2}{ }^{-1}$ at $\mathrm{pH}=7.9$. The changes of N/AA and EO/Si ratios reported on Figure 5 reflect those organic content variations.

In the most acidic domain range $(4.5 \leq \mathrm{pH}<5.5)$, in which $2 \mathrm{D}$ hexagonal mesostructures were obtained, the N/AA increase (from about 0.65 up to a value of $\approx 1$ ) accounts for the rise of the ionization degree of the acrylate functions expected for this weak polyacid ( $\mathrm{pKa}_{\mathrm{AA}} 4.8$ ). The number of negative charges on the PAA increases with $\mathrm{pH}$ what favors the interaction with $\mathrm{OC}$ in the formation of polyion complex (see Figure 1), and allows more OC to be integrated in the material. This is consistent with the increase of the pore diameter of the calcined materials from 5 to $5.7 \mathrm{~nm}$ (Table 1 and Figure $3 \mathrm{~b}$ ). The EO/Si ratio is almost constant $(\mathrm{EO} / \mathrm{Si} \approx 0.6$ ), which highlights the favorable hydrogen bond interactions between the ethylene oxide groups of PEO blocks and hydrolyzed silicic species $(\mathrm{Si}-\mathrm{OH})$ in this $\mathrm{pH}$ range.

At an intermediate $\mathrm{pH}(5.5<\mathrm{pH} \leq 6.9)$, the N/AA increase may reflect not only the decrease of the charge density of oligochitosan $\left(\mathrm{p} K \mathrm{a}_{\mathrm{OC}} 6.7\right)$ but also the increase of the PAA charge density, leading to an increase of the OC content relative to the DHBC in order to compensate the PAA charge in the PIC nanophase. Let us note that the fact that the amount of OC integrated in the material $\left(\mathrm{OC} / \mathrm{SiO}_{2}\right)$ remained constant within that $\mathrm{pH}$ range could be due either to the formation of a polyion complex richer in OC or to the development of favorable interactions between negatively charged silica species and OC species, which could also favor OC incorporation. Even if this last interaction cannot be totally ruled out, the increase of the mean pore diameter in the calcined materials synthesized at $3.9 \mathrm{wt} \%$ of DHBC (Table 1) argues in favor of an OC-richer polyion complex. In such conditions, a looser polyion complex rich in OC is expected to form, in accordance with the increased mesopore volume. The EO/Si decrease reflects the weaker hydrogen bond interactions between EO and silica species, which are expected due to the $\mathrm{pH}$-dependence of the charge density of silica species [40]. This decreased $\mathrm{EO} / \mathrm{SiOH}$ interaction with $\mathrm{pH}$ is in good accordance with the well-admitted mechanism of formation of Pluronic-templated mesostructured silica [5,41-43], in which

\begin{tabular}{|c|c|c|c|c|c|c|c|c|c|}
\hline $\mathrm{pH}$ & 4.5 & 4.9 & 5.3 & 5.5 & 6.0 & 6.5 & 6.9 & 7.4 & 7.9 \\
\hline wt $\% \mathrm{SiO}_{2}$ & 51.8 & 53.1 & 50.4 & 49.0 & 52.0 & 53.1 & 51.8 & 58.5 & 60.4 \\
\hline $\mathrm{DHBC}\left(\mathrm{mg} \cdot \mathrm{gsiO}^{-1}\right)$ & 553 & 536 & 528 & 545 & 480 & 456 & 468 & 370 & 361 \\
\hline $\mathrm{OC}\left(\mathrm{mg} \cdot \mathrm{gsiO}^{-1}\right)$ & 211 & 233 & 299 & 325 & 290 & 294 & 306 & 225 & 157 \\
\hline$D(\%)$ & 86 & 86 & 87 & 88 & 87 & 88 & 88 & 91 & 90 \\
\hline
\end{tabular}


the primary step for a good mesostructure to be obtained is entropy driven by hydrogen bonding between the silica oligomers and PEO chains [5]. Variations in the respective sizes of the two nanodomains of the system, (1) the polyion electrostatic complex core and (2) the PEO/inorganic corona, as a function of $\mathrm{pH}$, lead to changes of the interfacial curvature of the system that controls the mesostructure of the material. At $3.9 \mathrm{wt} \%$ of DHBC, the well-ordered 2D-hexagonal mesostructure of the $\mathrm{pH} 4.5-5.3$ domain, presenting purely cylindrical mesopores, thus evolves towards a mixture of less-ordered worm-like/lamellar structures with larger pore diameter and the subsequent appearance of a bimodal distribution of mesopores at higher $\mathrm{pH}$. It is noted that from $\mathrm{pH} 4.5$ to 6.9 , the $\mathrm{pH}$ increase leads to a decrease of the mean curvature of the mesostructure, as revealed by the increase of the pore diameter and/or the tendency to form domains of lamellar structures at the expense of 2D hexagonal structure domains. Let us add that these variations can be related to the increase in OC content in the PIC nanodomains.

At the highest $\mathrm{pH}$ values ( $\mathrm{pH} 7.4$ and 7.9), the N/AA ratio sharply drops whereas EO/Si further decreases. The low value of N/AA is quite surprising since the charge density of OC decreases strongly above $\mathrm{pH} 6.5$, and then even higher values of N/AA could be expected as a result of the necessary charge compensation in the PIC nanophase. Let us note that the low value of N/AA is associated with a significant porosity of the as-synthesized hybrid materials (see Figure S5 in Supporting Information File 1). Large mesopore volumes $\left(V_{\text {meso }}=0.39\right.$ and $0.29 \mathrm{~cm}^{3} \cdot \mathrm{g}^{-1}$ at $\mathrm{pH} 7.4$ and 7.9 , respectively) and large pore diameters $\left(d_{\text {pore }}=9.1\right.$ and $10.2 \mathrm{~nm}$ at $\mathrm{pH} 7.4$ and 7.9 , respectively) in the hybrid materials were obtained; they are close to the ones obtained on the calcined materials (Table 1). Those combined observations suggest that part of the oligochitosan molecules would be eluted from the material while the reaction medium is maintained for hours at $\mathrm{pH}$ above 7 , as it can be expected when considering the micellization $\mathrm{pH}$ range (Figure 1) The occurrence of mesoporosity in the dried hybrid materials is currently under investigation and will be discussed further in a forthcoming paper. The very low value of the $\mathrm{EO} / \mathrm{Si}$ ratio indicates a decay of the extent of the $\mathrm{SiOH} / \mathrm{EO}$ hydrogen bond interaction compared to the syntheses performed at lower $\mathrm{pH}$. Mesopore volumes (above $0.5 \mathrm{~cm}^{3} / \mathrm{g}$ ) and pore diameters (about $10 \mathrm{~nm}$ ) observed on the calcined materials (Figure 3 and Table 1) are much higher than at $\mathrm{pH}$ below 7 , suggesting that the PEO block was not trapped into silica walls of the materials but rather acted as a porogen agent contributing to the mesopore volume once the materials were calcined. Such an occurrence is reminiscent of the size increase of the structural mesopores of SBA-15 materials observed at temperature of synthesis higher than $80^{\circ} \mathrm{C}$, which reduces the solvation of the PEO chains and thus weakens the interaction between PEO and silica [44]. A similar effect was observed with the present PIC structure directing agent when performing a material synthesis at $\mathrm{pH} 6.5$ at $80{ }^{\circ} \mathrm{C}$ for 24 hours: the mesopore diameter of the calcined material increased from 5.9 to $12 \mathrm{~nm}$ and the mesopore volume from 0.25 to $0.95 \mathrm{~cm}^{3} \cdot \mathrm{g}^{-1}$ (Figure S6 in Supporting Information File 1). The material contained a lower amount of DHBC (EO/Si 0.4 and $315 \mathrm{mg} \cdot \mathrm{g}_{\mathrm{SiO} 2}{ }^{-1}$ instead of $\mathrm{EO} / \mathrm{Si} 0.5$ and $456 \mathrm{mg} \cdot \mathrm{g}_{\mathrm{SiO}}{ }^{-1}$ at $30{ }^{\circ} \mathrm{C}$ ) as it is the case for the synthesis performed at high $\mathrm{pH}$, and it is also slightly poorer in $\mathrm{OC}$ (N/AA 1.07 and $239 \mathrm{mg} / \mathrm{g}_{\mathrm{SiO} 2}{ }^{-1}$ instead of N/AA 1.1 and $294 \mathrm{mg} / \mathrm{g}_{\mathrm{SiO} 2}{ }^{-1}$ at $30^{\circ} \mathrm{C}$ ). Interestingly, the mesostructure observed on the TEM image (Figure S7 in Supporting Information File 1) of such a temperature-treated sample is similar to the short-range ordered cylindrical mesopores presenting honeycomb-like arrangement of the materials synthesized at pH 7.4 and 7.9, thus supporting the role of the weaker interaction between PEO and silica at those $\mathrm{pH}$. It is worth noting that the involvement of mediating cations ensuring the interface neutrality through a $\mathrm{N}^{0} \mathrm{Na}^{+} \mathrm{I}^{-}$pathway (in our case $\mathrm{Na}^{+}$coming from the sodium hydroxide solution used to adjust the $\mathrm{pH}$ ) that has been proposed in some studies [4] does not hold in this high $\mathrm{pH}$ material synthesis, since the $\mathrm{Na} / \mathrm{Si}$ molar ratio obtained from EDX measurements was too low $(\mathrm{Na} / \mathrm{Si} \approx 0.04)$ to support such an assembly.

The $\mathrm{pH}$-dependent mesoproperties of the PEO- $b$-PAA/OC PIC structuring agent can be depicted by defining an induced amphiphilic unit that determines the nature of the mesophase. This amphiphilic unit can be described as a ternary system constituted of OC, PEO- $b$-PAA and silica species. The core of the amphiphilic system is constituted by a polyion electrostatic complex of OC/PAA and the corona by the H-bonded assembly of PEO block and silica species. As the $\mathrm{pH}$ of the synthesis medium is increased (from pH 4.5 to 6.5), the extent of the electrostatic interactions increases and the hydrogen bond interaction with silica species weakens, whereas the condensation rate of silica increases. Figure 6 schematically depicts the different interactions involved in the formation of the hybrid precipitate, and how they vary with $\mathrm{pH}$, allowing us to tune the relative sizes of the electrostatic complex core and the PEO/inorganic corona of the amphiphilic unit. The $\mathrm{pH}$ sensitivity of the various interactions provided by this peculiar amphiphilic system allows tuning the mesostructure of the material from hexagonal to worm-like/lamellar simply by varying the $\mathrm{pH}$ of the reaction medium at $3.9 \mathrm{wt} \%$ of DHBC. At a lower DHBC concentration $(1.9 \mathrm{wt} \%)$, the mesostructure transformed from lamellar/ hexagonal at $\mathrm{pH} 4.5$ to purely lamellar at $\mathrm{pH}$ 6.5. Interestingly, the hybrid materials prepared in more dilute conditions exhibited N/AA (0.62 and 1.24 at $\mathrm{pH} 4.5$ and 6.5, respectively) and $\mathrm{EO} / \mathrm{Si}$ ( 0.56 and 0.48 at $\mathrm{pH} 4.5$ and 6.5 , respectively) ratios sim- 


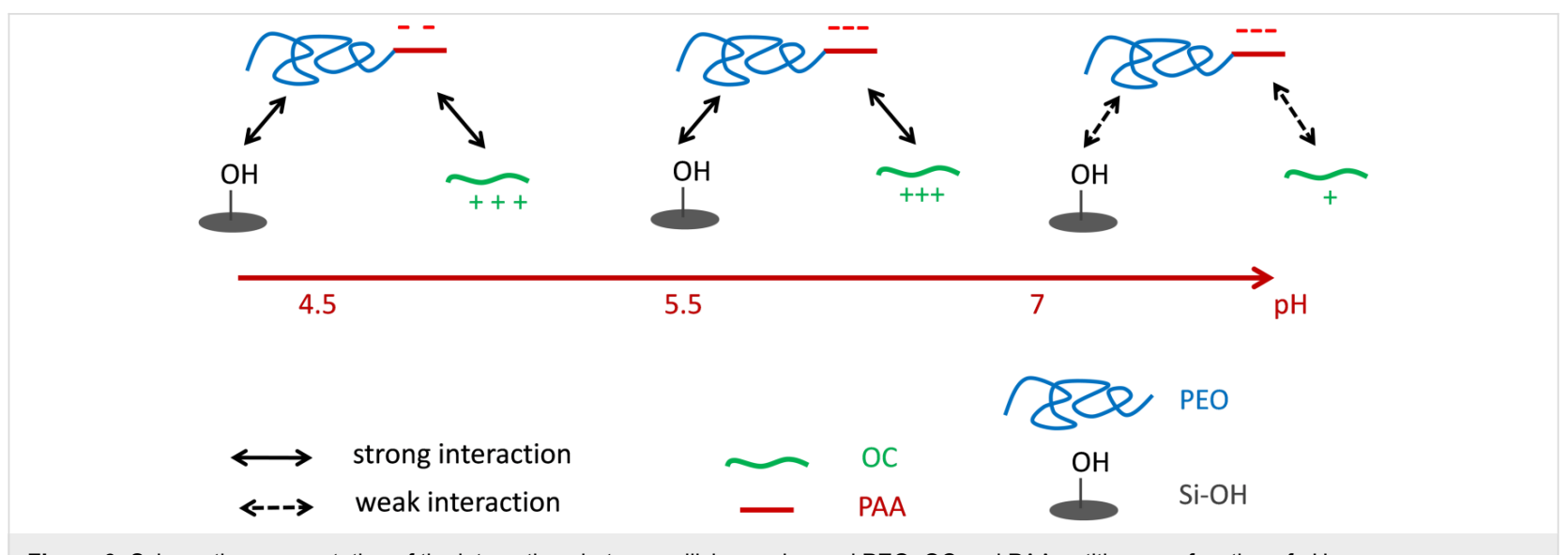

Figure 6: Schematic representation of the interactions between silicic species and PEO, OC and PAA entities as a function of pH.

ilar to those obtained at $3.9 \mathrm{wt} \%$ whereas the mesostructures were found to be rather different from those obtained at $3.9 \mathrm{wt} \%$. Several factors may be involved in the difference in mesostructures between the two concentrations of the reaction medium (hexagonal vs lamellar/hexagonal mixture at $\mathrm{pH} 4.5$ and short-range ordered worm-like/lamellar mixture vs purely lamellar at $\mathrm{pH}$ 6.5): the different silica condensation rates, the different quantities of ethanol released upon TEOS hydrolysis and their influence on the polymer solubility, and the amounts of water contained in both the hydrophilic PEO shell and the PIC core, which may swell differently the two different compartments.

\section{Conclusion}

In conclusion, mesoporous materials of various structures including 2D hexagonal, worm-like, and lamellar structures were formed by using polyion complex micelles as structure-directing agents under different $\mathrm{pH}$ conditions of material synthesis. As a weak polyacid-containing DHBC and a weak polybase were chosen as constituents of the polyion complexes, micelle formation occurs on a restricted $\mathrm{pH}$ domain between about 4.5 and 7. The silica framework is obtained by condensation of silicic species, which are formed by hydrolysis of the silicon alkoxide at $\mathrm{pH}$ 2. Due to the $\mathrm{pH}$ dependence of the PIC micelle properties, of the silica condensation rate, and of the PEOsilanol interactions, the variation of the $\mathrm{pH}$ of the reaction medium from 4.5 to about 8 led to considerable changes in the structural, textural and compositional properties of the materials.

After hydrolysis of TEOS in the presence of the polymers, the increase of the $\mathrm{pH}$ of the aqueous mixture between 4.5 and 7.9 leads to the formation of a macroscopic hybrid organic-inorganic precipitate. When the materials were synthesized in the $\mathrm{pH}$ 4.5-5.5 range, long-range ordered 2D hexagonal structures exhibiting pore diameters which regularly increase with $\mathrm{pH}$ were obtained. In the $\mathrm{pH}$ 5.7-6.5 range, a mixture of short- range ordered worm-like and lamellar structures was obtained; it appears to be a pure long-range ordered lamellar phase when the reaction medium was twice less concentrated. When the $\mathrm{pH}$ of the material synthesis exceeds $\mathrm{pH} 7$, cylindrical pore morphologies were obtained, exhibiting some short-range ordered $2 \mathrm{D}$ hexagonal arrangement. In the $\mathrm{pH}$ range 4.5-6.9, pore diameters were shown to increase progressively with $\mathrm{pH}$ up to $5.7 \mathrm{~nm}$, whereas they dramatically increase above $\mathrm{pH} 7$ exceeding $10 \mathrm{~nm}$. The variations of the structural and porous properties of the materials were shown to be related to variations of the compositions. Mesostructures with larger pore diameters or with a higher radius of curvature were obtained in the $\mathrm{pH}$ range $4.5-6.9$, in relation with increased content of the polybase (oligochitosan) in the PIC nanodomain (increased ratio between amine and acrylate functions).

In summary, the $\mathrm{pH}$ of the reaction medium appears to be a key parameter in the determination of the structural and textural characteristics of mesoporous materials whose synthesis is directed by polyion complex micelles. This is due to the variation of three essential properties as a function of $\mathrm{pH}$ : the extent of the electrostatic bonding between the weak polyelectrolytes, the extent of the hydrogen bond interaction between silanol and PEO ether groups, and finally, the silica condensation rate. As a complementary investigation, the influence of other synthesis parameters, which were identified to play a role in the structure determination, including the concentration of the reaction medium and the temperature, is currently under study.

\section{Supporting Information}

\section{Supporting Information File 1}

Additional experimental data.

[https://www.beilstein-journals.org/bjnano/content/ supplementary/2190-4286-10-14-S1.pdf] 


\section{Acknowledgements}

The authors would like to acknowledge Philippe Gaveau (Institut Charles Gerhardt Montpellier) for his help in NMR experiments, the "Laboratoire de Mesures Physiques de l'Université de Montpellier" for elemental analyses. The authors are also thankful to the MENRT (Ministry of National Education, Research and Technology), the ANR for ANR MESOPIC Project ANR-15-CE07-0005 and the Chemisyst Labex of Montpellier for financial support.

\section{ORCID ${ }^{\circledR}$ iDs}

Emilie Molina - https://orcid.org/0000-0002-0967-9836

Patrick Lacroix-Desmazes - https://orcid.org/0000-0002-0197-7062 Martin In - https://orcid.org/0000-0001-8074-180X

\section{References}

1. Huo, Q.; Margolese, D. I.; Ciesla, U.; Demuth, D. G.; Feng, P.; Gier, T. E.; Sieger, P.; Firouzi, A.; Chmelka, B. F.; Schüth, F.; Stucky, G. D. Chem. Mater. 1994, 6, 1176-1191. doi:10.1021/cm00044a016

2. Tanev, P. T.; Pinnavaia, T. J. Science 1995, 267, 865-867. doi:10.1126/science.267.5199.865

3. Bagshaw, S. A.; Prouzet, E.; Pinnavaia, T. J. Science 1995, 269 , 1242-1244. doi:10.1126/science.269.5228.1242

4. Zhao, D.; Huo, Q.; Feng, J.; Chmelka, B. F.; Stucky, G. D. J. Am. Chem. Soc. 1998, 120, 6024-6036. doi:10.1021/ja974025i

5. Sundblom, A.; Oliveira, C. L. P.; Pedersen, J. S.; Palmqvist, A. E. C. J. Phys. Chem. C 2010, 114, 3483-3492. doi:10.1021/jp100087z

6. Rubio, J.; Kitchener, J. A. J. Colloid Interface Sci. 1976, 57, 132-142. doi:10.1016/0021-9797(76)90182-x

7. Chaudhary, V.; Sharma, S. J. Porous Mater. 2017, 24, 741-749. doi:10.1007/s10934-016-0311-z

8. Zhao, D.; Feng, J.; Huo, Q.; Melosh, N.; Fredrickson, G. H.; Chmelka, B. F.; Stucky, G. D. Science 1998, 279, 548-552. doi:10.1126/science.279.5350.548

9. Brinker, C. J.; Scherer, G. W. Sol-Gel Science. The Physics and Chemistry of Sol-Gel Processing; Academic Press, 1990. doi:10.1016/c2009-0-22386-5

10. Kim, J. M.; Han, Y.-J.; Stucky, G. D.; Chmelka, B. F. Chem. Commun 2000, 2437-2438. doi:10.1039/b005608I

11. Kim, S.-S.; Karkamkar, A.; Pinnavaia, T. J.; Kruk, M.; Jaroniec, M. J. Phys. Chem. B 2001, 105, 7663-7670. doi:10.1021/jp010773p

12. Kim, S.-S.; Pauly, T. R.; Pinnavaia, T. J. Chem. Commun. 2000, 17, 1661-1662. doi:10.1039/b002856h

13. Jammaer, J.; Aerts, A.; D'Haen, J.; Seo, J. W.; Martens, J. A. J. Mater. Chem. 2009, 19, 8290-8293. doi:10.1039/b915273c

14. Martens, J. A.; Jammaer, J.; Bajpe, S.; Aerts, A.; Lorgouilloux, Y.; Kirschhock, C. E. A. Microporous Mesoporous Mater. 2011, 140, 2-8. doi:10.1016/j.micromeso.2010.09.018

15. Kerkhofs, S.; Willhammar, T.; Van Den Noortgate, H.; Kirschhock, C. E. A.; Breynaert, E.; Van Tendeloo, G.; Bals, S.; Martens, J. A. Chem. Mater. 2015, 27, 5161-5169. doi:10.1021/acs.chemmater.5b01772

16. Wang, Y.-Q.; Zheng, C.-M.; Liu, Z.-J.; Guo, M.-L. New J. Chem. 2015, 39, 7763-7767. doi:10.1039/c5nj01632k
17. Colmenares, M. G.; Simon, U.; Cruz, O.; Thomas, A.; Goerke, O.; Gurlo, A. Microporous Mesoporous Mater. 2018, 256, 102-110. doi:10.1016/j.micromeso.2017.08.002

18. Jammaer, J.; van Erp, T. S.; Aerts, A.; Kirschhock, C. E. A.; Martens, J. A. J. Am. Chem. Soc. 2011, 133, 13737-13745. doi:10.1021/ja205627t

19. Boissière, C.; Larbot, A.; van der Lee, A.; Kooyman, P. J.; Prouzet, E. Chem. Mater. 2000, 12, 2902-2913. doi:10.1021/cm991188s

20. Cui, X.; Zin, W.-C.; Cho, W.-J.; Ha, C.-S. Mater. Lett. 2005, 59, 2257-2261. doi:10.1016/j.matlet.2005.02.073

21. Jin, Z.; Wang, X.; Cui, X. J. Colloid Interface Sci. 2007, 307, 158-165. doi:10.1016/j.jcis.2006.11.006

22. Jin, Z.; Wang, X.; Cui, X. Microporous Mesoporous Mater. 2008, 108 183-192. doi:10.1016/j.micromeso.2007.03.042

23. Baccile, N.; Reboul, J.; Blanc, B.; Coq, B.; Lacroix-Desmazes, P.; In, M.; Gérardin, C. Angew. Chem., Int. Ed. 2008, 47, 8433-8437. doi:10.1002/anie.200802431

24. Birault, A.; Molina, E.; Carcel, C.; Bartlett, J.; Marcotte, N.; Toquer, G.; Lacroix-Desmazes, P.; Gerardin, C.; Wong Chi Man, M. J. Sol-Gel Sci. Technol. 2018, 4667. doi:10.1007/s10971-018-4667-1

25. Warnant, J.; Marcotte, N.; Reboul, J.; Layrac, G.; Aqil, A.; Jerôme, C.; Lerner, D. A.; Gérardin, C. Anal. Bioanal. Chem. 2012, 403, 1395-1404. doi:10.1007/s00216-012-5947-1

26. Houssein, D.; Warnant, J.; Molina, E.; Cacciaguerra, T.; Gérardin, C.; Marcotte, N. Microporous Mesoporous Mater. 2017, 239, 244-252. doi:10.1016/j.micromeso.2016.10.013

27. Mebarek, N.; Aubert-Pouëssel, A.; Gérardin, C.; Vicente, R.; Devoisselle, J.-M.; Bégu, S. Int. J. Pharm. 2013, 454, 611-620. doi:10.1016/j.ijpharm.2013.06.014

28. Molina, E.; Warnant, J.; Mathonnat, M.; Bathfield, M.; In, M.; Laurencin, D.; Jérôme, C.; Lacroix-Desmazes, P.; Marcotte, N.; Gérardin, C. Langmuir 2015, 31, 12839-12844. doi:10.1021/acs.langmuir.5b03221

29. Reboul, J.; Nugay, T.; Anik, N.; Cottet, H.; Ponsinet, V.; In, M.; Lacroix-Desmazes, P.; Gérardin, C. Soft Matter 2011, 7, 5836-5846. doi:10.1039/c1sm05230f

30. Trombotto, S.; Ladavière, C.; Delolme, F.; Domard, A. Biomacromolecules 2008, 9, 1731-1738. doi:10.1021/bm800157x

31. Brunauer, S.; Emmett, P. H.; Teller, E. J. Am. Chem. Soc. 1938, 60, 309-319. doi:10.1021/ja01269a023

32. Neimark, A. V.; Ravikovitch, P. I. Microporous Mesoporous Mater. 2001, 44-45, 697-707. doi:10.1016/s1387-1811(01)00251-7

33. Broekhoff, J. C. P.; de Boer, J. H. J. Catal. 1968, 10, 391-400. doi:10.1016/0021-9517(68)90154-1

34. Thommes, M.; Kaneko, K.; Neimark, A. V.; Olivier, J. P.; Rodriguez-Reinoso, F.; Rouquerol, J.; Sing, K. S. W. Pure Appl. Chem. 2015, 87, 1051-1069. doi:10.1515/pac-2014-1117

35. Berggren, A.; Palmqvist, A. E. C. J. Phys. Chem. C 2008, 112, 732-737. doi:10.1021/jp0766858

36. Léonard, A.; Blin, J. L.; Jacobs, P. A.; Grange, P.; Su, B. L. Microporous Mesoporous Mater. 2003, 63, 59-73. doi:10.1016/s1387-1811(03)00432-3

37. Muto, S.; Imai, H. Microporous Mesoporous Mater. 2006, 95, 200-205. doi:10.1016/j.micromeso.2006.05.023

38. Sierra, L.; Guth, J.-L. Microporous Mesoporous Mater. 1999, 27 , 243-253. doi:10.1016/s1387-1811(98)00258-3

39. Sierra, L.; Lopez, B.; Guth, J.-L. Microporous Mesoporous Mater. 2000, 39, 519-527. doi:10.1016/s1387-1811(00)00227-4 
40. Iler, R. K. The Chemistry of Silica: Solubility, Polymerization, Colloid and Surface Properties, and Biochemistry; Wiley: New York, NY, U.S.A., 1979.

41. Ruthstein, S.; Frydman, V.; Goldfarb, D. J. Phys. Chem. B 2004, 108 9016-9022. doi:10.1021/jp049133n

42. Blin, J. L.; Impéror-Clerc, M. Chem. Soc. Rev. 2013, 42, 4071-4082. doi:10.1039/c2cs35362h

43. Sundblom, A.; Palmqvist, A. E. C.; Holmberg, K. Langmuir 2010, 26, 1983-1990. doi:10.1021/la902144h

44. Galarneau, A.; Cambon, H.; Di Renzo, F.; Ryoo, R.; Choi, M.; Fajula, F. New J. Chem. 2003, 27, 73-79. doi:10.1039/b207378c

\section{License and Terms}

This is an Open Access article under the terms of the Creative Commons Attribution License

(http://creativecommons.org/licenses/by/4.0). Please note that the reuse, redistribution and reproduction in particular requires that the authors and source are credited.

The license is subject to the Beilstein Journal of

Nanotechnology terms and conditions:

(https://www.beilstein-journals.org/bjnano)

The definitive version of this article is the electronic one which can be found at: doi:10.3762/bjnano.10.14 